\title{
Evaluation of the effect of three supplementary oral hygiene measures on salivary mutans streptococci levels in children: A randomized comparative clinical trial
}

\author{
M. Manju ${ }^{1}$, P. Prathyusha ${ }^{2}$, Elizabeth Joseph ${ }^{3}$, Rupali Borkar Kaul ${ }^{4}$, \\ Srinivas L. Shanthraj ${ }^{5}$, Ntasha Sethi ${ }^{6}$
}

\begin{abstract}
'Department of Pedodontics and Preventive Dentistry, Dr. Syamala Reddy Dental College Hospital and Research Center, Munnekolala, Bengaluru, Karnataka, India, 2Department of Pedodontics and Preventive Dentistry, C.K.S Teja Institute of Dental Sciences, Tirupati, Andhra Pradesh, India,

${ }^{3}$ Department of Pedodontics and Preventive Dentistry, Pushpagiri College of Dental Sciences, Thiruvalla, Kerala, India,

${ }^{4}$ Department of Pedodontics and Preventive Dentistry, Darshan Dental College and Hospital, Udaipur, Rajasthan, India,

5Department of Pedodontics and Preventive Dentistry, Coorg Institute of Dental Sciences, Virajpet, Karnataka, India ${ }^{6}$ Consultant Pediatric Dentist, Total Dental Care, Najafgarh, New Delhi, India
\end{abstract}

\section{ABSTRACT}

Objective: The aim of this study was to evaluate and compare the effect of tongue scraping, tongue brushing, and saturated saline on salivary MS levels. Materials and Methods: A single-blinded, randomized, parallel group clinical trial was conducted in children aged 9-12 years. Total sample of 45 subjects were randomly assigned to three groups, that is, Group A, Group B, and Group C comprised of 15 each. Group A, Group B, and Group C were asked to do tongue scraping, tongue brushing and saturated saline rinsing twice daily, respectively for 21 days. Saliva samples, collected from the subjects on the baseline, $7^{\text {th }}$ day and $21^{\text {st }}$ day, were inoculated on mitis salivarius bacitracin agar and incubated at $37^{\circ} \mathrm{C}$ for $48 \mathrm{~h}$. The mean streptococcal colony forming counts were enumerated. The data were subjected to statistical analysis using Wilcoxon signed rank sum test for intragroup comparisons and Mann-Whitney U-test for intergroup comparisons. Results: Intragroup comparisons showed statistically significant reduction in MS levels $(P<0.01)$. However, the intergroup comparisons showed no statistically significant difference $(P>0.05)$. Conclusion: The oral hygiene measures evaluated proved equal efficacy in reducing the colony counts. Hence, there is a need to emphasize the importance of incorporating supplementary oral hygiene measures in daily oral care.

Key words: Dental caries, mutans streptococci, oral hygiene, saliva

\section{INTRODUCTION}

Dental caries is currently conceptualized as a multifactorial disease where there is an interaction of three principal factors. The host (saliva and teeth), the microflora (plaque), the substrate (diet), and a fourth factor, the time has been included in the keyes circle of caries formation. Since the time the chemo-parasitic theory was postulated by W.D. Miller,
This is an open access article distributed under the terms of the Creative Commons Attribution-NonCommercial-ShareAlike 3.0 License, which allows others to remix, tweak, and build upon the work non-commercially, as long as the author is credited and the new creations are licensed under the identical terms.

For reprints contact: reprints@medknow.com

How to cite this article: Manju M, Prathyusha P, Joseph E, Kaul RB, Shanthraj SL, Sethi N. Evaluation of the effect of three supplementary oral hygiene measures on salivary mutans streptococci levels in children: A randomized comparative clinical trial. Eur J Dent 2015;9:462-9.

DOI: $10.4103 / 1305-7456.172616$ 
studies have revealed that microorganisms play the major role in the causation of dental caries. ${ }^{[1,2]}$ Among the microorganisms, mutans streptococci (MS) have been regarded as the major culprit. ${ }^{[3-5]}$ It has been established that the number of MS in saliva is directly linked to its number colonized on hard and soft tissue surfaces that are the basis for salivary counting of MS. ${ }^{[5,6]}$ A subject with low salivary MS count has a lower risk of developing caries lesions and the caries risk threshold is usually set to values $\geq 10^{5}$ colony forming units per milliliter $(\mathrm{CFU} / \mathrm{ml})$ of saliva. ${ }^{[7]}$

The human oral cavity provides nutrition and facilitates the growth of microorganisms. Tooth brushing that is the most extensively practiced oral hygiene procedure cleans only selected parts of the tooth and the gingiva. Even adjunctive mechanical and chemical methods of oral hygiene measures such as floss, water jet devices, toothpicks are employed, but their potential is limited to tooth surfaces and gingiva.

It has been observed that tongue always remained a neglected part in the oral cavity. Its surface texture contributes significantly to plaque formation and accumulation. The papillary makeup of the tongue dorsum forms a distinctive site with fissures, grooves and papillated areas that provides a large surface area for accretion of microorganisms. ${ }^{[8,9]}$ The oral surfaces are colonized by over 500 bacterial species, and tongue has the largest bacterial load that makes the greatest contribution to bacteria found in saliva. ${ }^{[10]}$ More than 100 bacteria may be attached to a single epithelial cell on top of the tongue, whereas only about 25 bacteria are attached to each cell in other areas of the oral cavity. ${ }^{[11]}$

Although there is continuous desquamation of tongue epithelium, the dorsum of the tongue is hardly ever free from staphylococci and streptococci. It has been suggested that teeth, gingiva, and tonsils can be colonized by tongue bacteria, which originate mainly from the posterior region. ${ }^{[12]}$

Since dental caries and gingival diseases are both believed to be caused by microorganisms, it is appropriate to reduce the number of microorganisms in all areas of the oral cavity, including the tongue. This can be achieved by various home oral hygiene measures. Nevertheless, in ancient times tongue scraping and brushing were consistently practiced but it has been overlooked in the recent past. ${ }^{[13,14]}$

Earlier mouth rinses have been formulated for cosmetic reasons rather than the control of dental and periodontal diseases. Of late, quite a number of chemical agents, which are mostly synthetic compounds, have been used for control of dental plaque, eradication of harmful oral microorganisms, against halitosis, etc. ${ }^{[15]}$ Many agents used as rinses have the potential to cause local damage to tissues, if not systemic toxicity. Salt water rinses are outmoded, but a very effective bactericidal agent that can be safely used in the mouth. However, saturated salt water rinses have never been popular, most likely because of unfavorable taste. ${ }^{[6]}$

Tooth brushing alone is not enough to reduce the cariogenic bacteria in the mouth, supplementary measures such as tongue cleaning and mouth rinsing may also have an added effect in reducing MS in the oral cavity. There is a relative dearth of studies regarding the efficacy of these simple adjunctive procedures on MS in children. Hence, the aim of this study was to evaluate and compare the effects of the tongue scraping, tongue brushing and saturated saline on salivary MS levels.

\section{MATERIALS AND METHODS}

The present study was a single-blinded, randomized, parallel group clinical trial carried out in an orphanage in Bengaluru city, Karnataka, India. Signed consent from the authorities of the orphanage and verbal consent of the children were obtained after explaining the nature of the study. The proposed research protocol and written informed consent was reviewed by the Institutional Ethical Committee Board and clearance was obtained (Ref No: 453/2008). Clinical examinations were carried out at the orphanage by a single examiner.

The number of decayed, missing, filled surfaces of primary and permanent teeth (dmfs/DMFS) for each participant were recorded according to WHO diagnostic criteria for dental caries. After reviewing the medical records and complete oral examination using the WHO format, 45 subjects aged 9-12 years fulfilling the inclusion criteria were selected.

\section{Inclusion criteria}

- Subjects in the age group of 9-12 years

- Children with DMFT/deft with minimum score of 2

- Subjects receiving similar diet

- No history of fluoride treatment for past 3-4 weeks

- No history of current or recent antibiotic usage at least for the past 1-month

- No history of professional oral hygiene measures for past 3-4 weeks. 


\section{Study design}

Based on the data from the pilot study and fixing a at $5 \%$, the sample size obtained for each group was 15 ; thus, total sample size was 45 . The entire sample size of 45 subjects was randomly divided by lottery method into three groups. Group A (15 subjects), Group B (15 subjects), Group C (15 subjects) were asked to do tongue scraping, tongue brushing, and saturated saline rinsing twice daily (once in the morning and once after dinner) after tooth brushing, respectively for 21 days. This was a single-blinded study as the investigator who collected the saliva samples was unaware about the sampling of the groups. At the start of the study, baseline saliva samples were collected by spitting method into sterile sample collection bottles for all the subjects to establish MS level.

Group A subjects used stainless steel tongue scraper to scrape the dorsum of tongue twice daily after routine tooth brushing under the supervision of a monitor. With light pressure, two pulling strokes had to be given along the linea mediana and at the borders of the lateral sides of the tongue. Participants were asked to spit out the excess saliva that has been accumulated on the tongue. The scraper had been cleaned under running water for removing the debris. ${ }^{[6,14]}$

Group B participants were asked to brush the dorsum of the tongue using soft multi-tufted nylon toothbrush twice daily by three back and forth strokes along the linea mediana and at each lateral part of the tongue. Participants were asked to spit out the excess saliva. The brush had to be cleaned under running water for removing the debris. ${ }^{[14]}$

Group C participants were asked to use saturated saline that was prepared with the use of measuring cups and spoons. 13.5 teaspoons of salt were diluted in one cup of water. The solution was bottled and dispensed to the participants in Group C. The monitor was trained to instruct the subjects in the rinsing procedure. The monitor distributed the participants $10 \mathrm{ml}$ of the rinse in disposable cups and the subjects were asked to swish the solution in the mouth for $30 \mathrm{~s}$ twice daily. After rinsing, the subjects expectorated into the cups and placed them in a waste can and were instructed not to eat/drink/rinse for $30 \mathrm{~min}$. The saturated saline solution is defined as nine teaspoons of salt per $2 / 3$ cup of water (US army guidelines). ${ }^{[6]}$ All oral hygiene procedures done by the groups were being monitored.

\section{Method of saliva collection}

The baseline saliva samples were collected from each participant before the clinical trial to establish Streptococcusmutans level.Participantschewed a standard piece of paraffin wax, for 5 min and expectorated $1-2 \mathrm{ml}$ of saliva directly into the sterile collection bottles on the $7^{\text {th }}$ day and $21^{\text {st }}$ day. The stimulated saliva samples were collected in the mid-morning with no eating/drinking for $2 \mathrm{~h}$ prior to sampling except water. A total of three saliva samples were obtained from the participants of the study. The saliva samples of all the participants were recognized by a code number during sample collection and microbiological analysis. At each visit, an intraoral clinical examination was accomplished to detect unfavorable soft or hard tissue reactions to the supplementary oral hygiene procedures.

\section{Microbiological method}

The saliva samples were subjected immediately for microbiological analysis to assess the MS level. The saliva samples were diluted in $0.05 \mathrm{M}$ phosphate buffer ( $\mathrm{pH} 7.0$ ) to the serial dilutions of $1 / 10^{3}$, agitated for $30 \mathrm{~s}$ on a vortex mixer. One milliliter of saliva sample was inoculated into mitis salivarius bacitracin agar $(\mathrm{MSB})^{[16]}$ using pour plate method. The agar plates were incubated at $37^{\circ} \mathrm{C}$ for $48 \mathrm{~h}$ under $10 \% \mathrm{CO}_{2}$ anaerobic conditions. MS colonies were identified as round or spherical, convex, raised, and dark blue irregular colonies [Figure 1]. The number of MS colonies per milliliter of saliva on each plate was enumerated using the colony counter. Semi-quantification of the number of colonies was done by multiplying the actual colony count with its dilution factor.

\section{Statistical analysis}

The obtained values were tabulated and subjected to statistical analysis. The data were analyzed using Statistical Package for the Social Sciences (SPSS 19) software with Kruskal-Wallis Chi-square test for overall group comparison. Intragroup comparison of differences in salivary MS levels between baseline and $7^{\text {th }}$ day, baseline and $21^{\text {st }}$ day and between the $7^{\text {th }}$ day and $21^{\text {st }}$ day were done using Wilcoxon signed rank sum test. Intergroup comparisons of salivary MS counts were done using Mann-Whitney U-test at baseline, $7^{\text {th }}$ day and $21^{\text {st }}$ day.

\section{RESULTS}

Mean and standard deviation values of salivary MS counts (log values) showed that the bacterial count were higher in Group A followed by Group B and Group C at baseline. But, the difference in MS count $(\mathrm{CFU} / \mathrm{ml})$ 
between the groups at different time intervals were not statistically significant $(P>0.05)$ [Table 1 and Graph 1 ]. Group baseline measurements only were compared to ascertain if there were any differences among the groups before the start of the study.

Intragroup comparisons indicated that there was a statistically significant $(P<0.01)$ decrease in mean salivary MS counts $(\mathrm{CFU} / \mathrm{ml})$ on the $7^{\text {th }}$ day when compared to baseline. The decrease in $\mathrm{CFU} / \mathrm{ml}$ from baseline to $21^{\text {st }}$ day and from the $7^{\text {th }}$ day to $21^{\text {st }}$ day was similarly found to be statistically significant $(P<0.01)$ [Table 2].

Intergroup comparisons depicted showed no significant difference in MS counts between Group A, $\mathrm{B}$ and $\mathrm{C}$ at baseline, $7^{\text {th }}$ day and $21^{\text {st }}$ day [Table 3]. There is no significant difference between Group A and Group C on day 21 even though $P=0.033$ because the level of significance (alpha) will be changed to $0.05 / 3$ that is 0.0167 (approximately $=0.02$ ). Since $P>0.02$, we conclude that there is no significant difference.

\section{DISCUSSION}

In the present study, the effect of three supplementary oral hygiene measures on salivary MS levels in children was evaluated. In the current study, there was a gradual reduction in S. mutans count from baseline to $7^{\text {th }}$ day and also from $7^{\text {th }}$ day to $21^{\text {st }}$ day. The results showed that at the end of the clinical trial all three supplementary oral hygiene measures, that is, tongue scraping, tongue brushing and saturated saline proved to be equally effective in reducing the colony counts. In order to produce a long-lasting effect on the reduction of microorganisms, all the above procedures should be practiced on a day to day basis.

It has been indicated that the tongue dorsum is barely free from microorganisms, although there is endless shedding of tongue epithelium. ${ }^{[12]}$

Gilmore and Bhaskar in 1972 opined that tongue brushing reduced the microorganisms on the tongue, which formed plaque in vitro. ${ }^{[17]}$ Axelsson et al. in 1987 found a significant reduction of S. mutans after professional tooth cleaning and tongue scraping. ${ }^{[18]}$ These studies suggested that oral hygiene measures should include the dorsum of tongue, especially in patients, who have endogenously high levels of S. mutans inhabiting in the oral cavity.

The present study outcomes were comparable with a study that evaluated the efficacy of tongue scraping, Listerine oral care strips, saturated saline rinses once

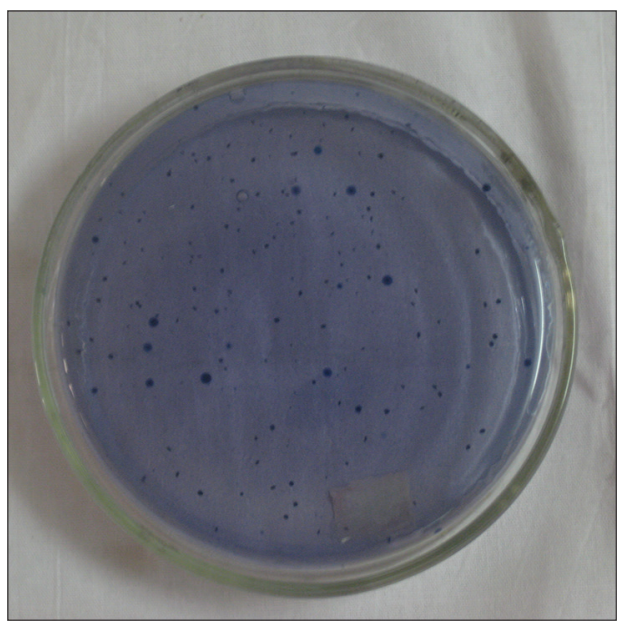

Figure 1: Colony morphology

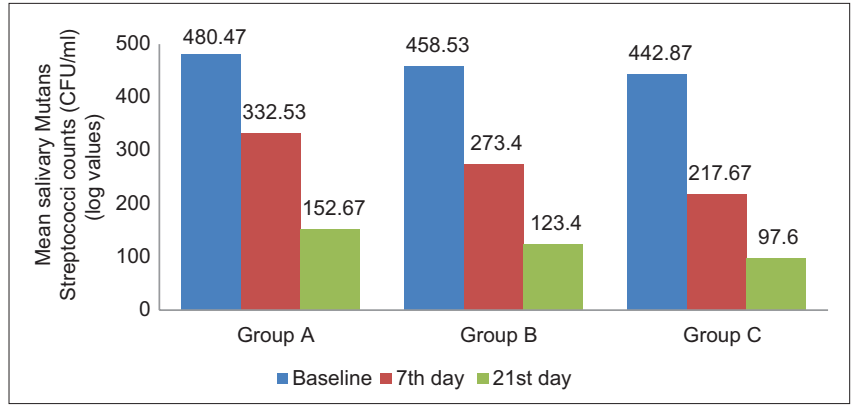

\begin{tabular}{lccc}
\hline & Group A & Group B & Group C \\
\hline Baseline & 480.47 & 458.53 & 442.87 \\
$7^{\text {th }}$ day & 332.53 & 273.4 & 217.67 \\
$21^{\text {st }}$ day & 152.67 & 123.4 & 97.6 \\
\hline
\end{tabular}

Graph 1: Mean salivary mutans streptococci counts (log values) of Group A, Group B and Group C at baseline, $7^{\text {th }}$ day, $21^{\text {st }}$ day

\begin{tabular}{|c|c|c|c|c|c|c|c|c|c|c|c|c|}
\hline \multirow[t]{2}{*}{ Group } & \multicolumn{4}{|c|}{ Baseline } & \multicolumn{4}{|c|}{$7^{\text {th }}$ day } & \multicolumn{4}{|c|}{$21^{\text {st }}$ day } \\
\hline & Mean & SD & $\begin{array}{c}\text { Kruskal-Wallis } \\
\text { Chi-square }\end{array}$ & $P$ & Mean & SD & $\begin{array}{c}\text { Kruskal-Wallis } \\
\text { Chi-square }\end{array}$ & $P$ & Mean & SD & $\begin{array}{c}\text { Kruskal-Wallis } \\
\text { Chi-square }\end{array}$ & $P$ \\
\hline $\bar{A}$ & 480.47 & 233.74 & 0.232 & $0.890^{*}$ & 332.53 & 241.31 & 1.992 & $0.369^{*}$ & 152.67 & 111.45 & 5.631 & $0.060^{*}$ \\
\hline$B$ & 458.53 & 195.65 & & & 273.40 & 132.96 & & & 123.40 & 51.23 & & \\
\hline $\mathrm{C}$ & 442.87 & 201.13 & & & 217.67 & 57.45 & & & 97.60 & 56.34 & & \\
\hline
\end{tabular}

*Not significant. SD: Standard deviation, MS: Mutans streptococci 


\begin{tabular}{|c|c|c|c|c|c|c|}
\hline \multirow[t]{2}{*}{ Groups } & \multicolumn{2}{|c|}{$\begin{array}{c}\text { Baseline } \\
\text { versus } 7^{\text {th }} \text { day }\end{array}$} & \multicolumn{2}{|c|}{$\begin{array}{c}\text { Baseline } \\
\text { versus } 21^{\text {th }} \text { day } \\
\end{array}$} & \multicolumn{2}{|c|}{$\begin{array}{c}7^{\text {th }} \text { day versus } \\
21^{\text {st }} \text { day }\end{array}$} \\
\hline & $Z$ & $P$ & $Z$ & $P$ & $Z$ & $P$ \\
\hline$A$ & -2.784 & $0.005^{\star *}$ & -3.408 & $0.001^{* *}$ & -3.408 & $0.001^{\text {** }}$ \\
\hline$B$ & -3.124 & $0.002^{* *}$ & -3.408 & $0.001^{* *}$ & -3.296 & $0.001^{* *}$ \\
\hline C & -3.351 & $0.001^{* *}$ & -3.408 & $0.001^{* *}$ & -3.409 & $0.001^{* *}$ \\
\hline
\end{tabular}

\begin{tabular}{|c|c|c|c|c|c|c|}
\hline \multirow[t]{2}{*}{ Groups } & \multicolumn{2}{|c|}{ Baseline } & \multicolumn{2}{|c|}{$7^{\text {th }}$ day } & \multicolumn{2}{|c|}{$21^{\text {st }}$ day } \\
\hline & $z$ & $P$ & $Z$ & $P$ & $Z$ & $P$ \\
\hline$A$ versus $B$ & 0.000 & $1.000^{*}$ & -0.539 & $0.590^{*}$ & -0.498 & $0.619^{\star}$ \\
\hline$B$ versus $C$ & -0.415 & $0.678^{*}$ & -0.560 & $0.575^{*}$ & -1.888 & $0.059^{*}$ \\
\hline$A$ versus $C$ & -0.415 & $0.678^{*}$ & -1.556 & $0.120^{*}$ & -2.137 & $0.033^{*}$ \\
\hline
\end{tabular}

daily for 7 days in reducing MS levels in adults. ${ }^{[6]}$ All three groups demonstrated a substantial reduction in colony counts after the start of the study.

Very few studies had been conducted on the ability of supplementary oral hygiene measures in reducing salivary MS levels in children. Rupesh et al. compared and evaluated the effects of tongue scraping and tongue brushing on salivary MS levels in children. ${ }^{[19]}$ There had been statistically significant reduction after 10 days and 21 days. It was observed that both tongue scraping and tongue brushing were equally effective. The $7^{\text {th }}$ day examination of the microbial count was done in our study to see the intermediate effect and also to check the adverse effects of these adjunctive oral hygiene measures.

Subjects with age ranging between 9 and 12 years were chosen as many permanent teeth will be erupting with a period of high caries activity. ${ }^{[20]}$ Subjects having all levels of oral hygiene were included in the study to see if the supplementary measures were applicable in subjects having different baseline MS. Oral prophylaxis were not carried out so as to conduct the study with the existing levels of oral microflora. The frequency and form of intake of cariogenic diet happen to be essential factors in the development of dental caries. ${ }^{[21]}$ The diet factor had to be controlled for giving all the groups the best possibility of demonstrating the efficacy against MS. Thus, the study was conducted in an orphanage with participants consuming the similar diet. Baseline measurements, when compared, ascertained that there were no significant differences between group means. So, groups was statistically similar before the start of the study.

The tests performed on stimulated saliva is preferred as it is more reliable compared to unstimulated saliva. ${ }^{[7]}$ Stimulated saliva was collected by having subjects chew on a piece of paraffin to stimulate the flow of saliva and to dislodge $S$. mutans from the teeth. ${ }^{[7]}$ Subjects were asked not to eat or drink for $2 \mathrm{~h}$ prior sample collection. The reason following this is diet may influence the microbial level of the oral cavity. Saliva is used for the bacterial count in the study as saliva represents the total oral load of microorganisms. ${ }^{[5]}$ Whereas, plaque samples were not used as plaque has to be collected from a specific site, and it differs from tooth to tooth. Studies by Mundorff et al. ${ }^{[22]}$ justified that the number of $S$. mutans in dental plaque sample does not describe the variation in caries better compared to the bacterial count in stimulated whole saliva. Counting of bacteria in saliva for assessment of mechanical means of tongue cleaning is justified as the removal of bacterial niches present on the tongue surface contributes in the reduction of the total number of bacteria.

For the present study, MSB agar was selected for colony count using pour plate method. The addition of $0.2 \mathrm{U} / \mathrm{ml}$ bacitracin and $20 \%$ sucrose led to an improved medium (MSB) with high selectivity for S. mutans. ${ }^{[7,23]}$ Selectivity of MS was further improved by the supplementation with $1 \%$ potassium tellurite to MSB agar. The determination of salivary MS is based on two main properties of these bacteria. In distinction to other oral bacteria: MS can grow in a milieu with a high sucrose concentration and are immune to specific antibiotic, bacitracin.

Conventional culturing for the detection and quantitation of microbes produces predictive results if strict adherence to procedures is followed such as sterile lab conditions, strict anaerobic/aerobic protocols. However, culturing techniques are usually laborious and sometimes unreliable because they depend on morphology and susceptibility to bacitracin that can be considered as a limitation in the current study. At present, genetic advances such as a species-specific polymerase chain reaction (PCR) based on the dextranase or glucosyltransferase gene sequences have been reported to be useful for detecting $S$. mutans in saliva. ${ }^{[24,25]}$ PCR demonstrates high specificity, sensitivity, and reliable quantitative 
results. As detection by conventional PCR does not discriminate between live or dead bacteria, it may be necessary to combine PCR with other methods to evaluate the presence of viable cells. One way to overcome this problem may involve methods like combined biological and enzymatic amplification of PCR, in which only living cells seem to be detected, or reverse transcription-PCR where the target for detection are specific mRNAs. ${ }^{[26]}$

There are studies showing both negative as well as positive associations between tongue hygiene and bacterial count. In contrast to a present study Menon and Coykendall stated insignificant reduction in bacterial population after tongue scraping. ${ }^{[27]}$ The probable reason could be that in their study tongue scraping was done only once, and the bacterial population was so large that scraping removed only a small portion. Another study by Quirynen et al. evaluated the effect of tongue cleaners on microbial load and failed to prove that tongue cleaning significantly reduces the bacterial load. ${ }^{[28]}$ The variable results could because they evaluated both aerobic and anaerobic microflora and used nonselective blood agar plates. The difficulty in reducing the bacterial load on the tongue is implied to innumerable depressions that provide ideal niches for bacterial growth and shelter from cleaning actions. ${ }^{[8]}$

In the present study, the understanding for the reduction in the bacterial count in tongue brushing group may be because the bristles sweep between papillae and remove microorganisms. ${ }^{[29]}$ In tongue scraping group, the reduction was probably due to the removal of tongue coating by the stiff stainless steel tongue blade. Gondhalekar et al. evaluated the effect of tongue scraping and tongue brushing on oral MS level and proved its effectiveness. ${ }^{[30]}$ Various studies proved the positive association of tongue cleaning and reduction in the microbial count and also established the importance of mechanical cleaning of the tongue. ${ }^{[31-35]}$

De Boever and Loesche found significant differences in samples taken from the tongue in patients with fissured tongues as compared to patients with smooth tongues. They also found differences in total CFU in patients with presence of tongue coating compared to patients without tongue coating. In their study, tongue cleaning combined with the use of chlorhexidine rinse and paste, which explains the possibility of $74 \%$ bacterial reduction on the tongue due to combined mechanical and chemical method. ${ }^{[36]}$

A study by Casemiro et al. demonstrated that tongue cleaning associated with tooth brushing minimizes halitosis and reduces the facultative aerobic and anaerobic microbiota on the tongue surface. ${ }^{[31]}$ The results confirmed the importance of mechanical cleaning of the tongue. Counting of salivary bacteria for evaluation of mechanical methods of tongue cleaning is justified since the removal of bacterial niches, present on tongue surface, contributes to the reduction of the total number of bacteria. The results of this study may have been influenced by factors such as diet (quality and amount). Thus, it is not possible to assure that the quantity of bacteria present on the tongue was same at all evaluation periods that can be considered as a limitation. However in the present study as the diet was controlled, it was appropriate to compare the efficacy of supplementary methods in decreasing the bacterial counts in the oral cavity.

The efficacy of salt water rinses is due to the osmotic phenomenon, which contributes to dehydration and bacterial death. An investigation by Rupesh et al. ${ }^{[37]}$ proved that children using saturated saline rinse and alum rinse showed statistically significant reductions in salivary $S$. mutans counts from baseline after $10^{\text {th }}$ day and $21^{\text {st }}$ day. The present study has also established that saturated salt water rinses could play an important role in reducing colony count like other commercial mouth rinses.

No adverse effect on oral soft or hard tissue was detected after implementation of adjunctive oral hygiene procedures for a 21 day period.

In a nutshell, as professional care cannot be obtained daily, the personal care should form an important aspect of oral hygiene maintenance no matter how sophisticated the dental procedures have become. The supplementary oral hygiene measures evaluated here are cost effective and less time is needed to carry out the procedure. These adjuncts should serve as supplements but not as substitutes for tooth brushing. The quantification of the amount as well as a proportion of the pathogens in relation to other oral bacteria is helpful in assessing the caries risk.

Each patient and the parent in pediatric dental practice should be taught the proper oral hygiene measures and should take the responsibility for his or her own oral health on a daily basis. There is a demand for comprehensive educational programs to encourage good oral health and give a preventive education about correct oral hygiene practices.

As this study was of short-term, long-term efficacy of supplementary oral hygiene measures should be 
examined in a large number of subjects in future. Further scope lies in the long-term evaluation of the effectiveness and side effects of adjunctive oral hygiene measures.

\section{CONCLUSION}

After implementation of supplemental oral hygiene measures there was statistically significant reduction in salivary MS levels when comparisons were made at baseline, $7^{\text {th }}$ day and $21^{\text {st }}$ day, within the three groups that is Group A, B, and C. However, the intergroup comparisons showed statistically no significant difference. All the oral hygiene measures, that is, tongue scraping, tongue brushing and saturated saline showed equal efficacy in reducing the colony counts. This study, therefore, suggests that tooth brushing alone is not enough to reduce the cariogenic bacteria in the mouth, supplementary measures such as tongue cleaning and mouth rinsing provide an added beneficial effect.

\section{Acknowledgement}

The authors would like to thank Dr. S. Rupesh, Associate Professor at Department of Pedodontics and Preventive Dentistry, Pushpagiri College of Dental Sciences, Perumthuruthy, Kerala, India for the expert advice in this dissertation process.

\section{Financial support and sponsorship}

Nil.

\section{Conflicts of interest}

There are no conflicts of interest.

\section{REFERENCES}

1. Shafer WG, Maynard KH, Barnet ML. A Textbook of Oral Pathology. $4^{\text {th }}$ ed. Philadelphia: W.B Sunders Company; 1993. p. 40

2. Kristoffersson K, Gröndahl HG, Bratthall D. The more Streptococcus mutans, the more caries on approximal surfaces. J Dent Res 1985;64:58-61.

3. Sakeenabi B, Hiremath SS. Dental caries experience and salivary Streptococcus mutans, lactobacilli scores, salivary flow rate, and salivary buffering capacity among 6-year-old Indian school children. J Int Soc Prev Community Dent 2011;1:45-51.

4. Nishikawara F, Katsumura S, Ando A, Tamaki Y, Nakamura Y, Sato K, et al. Correlation of cariogenic bacteria and dental caries in adults. J Oral Sci 2006;48:245-51.

5. Pannu P, Gambhir R, Sujlana A. Correlation between the salivary Streptococcus mutans levels and dental caries experience in adult population of Chandigarh, India. Eur J Dent 2013;7:191-5.

6. White GE, Armaleh MT. Tongue scraping as a means of reducing oral mutans streptococci. J Clin Pediatr Dent 2004;28:163-6.

7. Brambilla E, García-Godoy F, Strohmenger L. Principles of diagnosis and treatment of high-caries-risk subjects. Dent Clin North Am 2000;44:507-40, vi.

8. Matsui M, Chosa N, Shimoyama Y, Minami K, Kimura S, Kishi M. Effects of tongue cleaning on bacterial flora in tongue coating and dental plaque: A crossover study. BMC Oral Health 2014;14:4.

9. Allaker RP, Waite RD, Hickling J, North M, McNab R, Bosma MP, et al.
Topographic distribution of bacteria associated with oral malodour on the tongue. Arch Oral Biol 2008;53 Suppl 1:S8-12.

10. Loesche WJ, Kazor C. Microbiology and treatment of halitosis. Periodontol 2000 2002;28:256-79.

11. Yaegaki K, Coil JM. Examination, classification, and treatment of halitosis; clinical perspectives. J Can Dent Assoc 2000;66:257-61.

12. Danser MM, Gómez SM, Van der Weijden GA. Tongue coating and tongue brushing: A literature review. Int J Dent Hyg 2003;1:151-8.

13. Christen AG, Swanson BZ Jr. Oral hygiene: A history of tongue scraping and brushing. J Am Dent Assoc 1978;96:215-9.

14. Christensen GJ. Why clean your tongue? J Am Dent Assoc 1998;129:1605-7.

15. Kocak MM, Ozcan S, Kocak S, Topuz O, Erten H. Comparison of the efficacy of three different mouthrinse solutions in decreasing the level of Streptococcus mutans in saliva. Eur J Dent 2009;3:57-61.

16. Wan AK, Seow WK, Walsh LJ, Bird PS. Comparison of five selective media for the growth and enumeration of Streptococcus mutans. Aust Dent J 2002;47:21-6.

17. Gilmore EL, Bhaskar SN. Effect of tongue brushing on bacteria and plaque formed in vitro. J Periodontol 1972;43:418-22.

18. Axelsson P, Kristoffersson K, Karlsson R, Bratthall D. A 30-month longitudinal study of the effects of some oral hygiene measures on Streptococcus mutans and approximal dental caries. J Dent Res 1987;66:761-5.

19. Rupesh S, Winnier JJ, Nayak UA, Rao A, Reddy V, Peter J. The comparative evaluation of the effects of tongue cleaning on salivary levels of mutans streptococci in children. Int J Dent Hyg 2012;10:107-12.

20. Mourughan K, Suryakanth MP. Evaluation of an alum-containing mouthrinse for inhibition of salivary Streptococcus mutans levels in children - A controlled clinical trial. J Indian Soc Pedod Prev Dent 2004;22:100-5.

21. Mcdonald JL. Nutritional considerations for pediatric dental patient. In: McDonald RE, Avery DR, editors. Dentistry for the Child and adolescent. $5^{\text {th }}$ ed. St.Louis: The C.V. Mosby Company;1996. p. 287-300

22. Mundorff SA, Eisenberg AD, Leverett DH, Espeland MA, Proskin HM. Correlations between numbers of microflora in plaque and saliva. Caries Res 1990;24:312-7.

23. Saravia ME, Nelson-Filho P, Silva RA, De Rossi A, Faria G, Silva LA et al. Recovery of mutans streptococci on MSB, SB-20 and SB-20M agar media. Arch Oral Biol 2013;58:311-6.

24. Nurelhuda NM, Al-Haroni M, Trovik TA, Bakken V. Caries experience and quantification of Streptococcus mutans and Streptococcus sobrinus in saliva of Sudanese schoolchildren. Caries Res 2010;44:402-7.

25. Jiang Q, Yu M, Min Z, Yi A, Chen D, Zhang Q. AP-PCR detection of Streptococcus mutans and Streptococcus sobrinus in caries-free and caries-active subjects. Mol Cell Biochem 2012;365:159-64.

26. Sachse K, Frey J, editors. Methods in Molecular Biology: PCR Detection of Microbial Pathogens. Vol. 216. Totowa, N.J.: Humana Press Inc. 2003.

27. Menon MV, Coykendall AL. Effect of tongue scraping. J Dent Res 1994;73:1492.

28. Quirynen M, Avontroodt P, Soers C, Zhao H, Pauwels M, van Steenberghe D. Impact of tongue cleansers on microbial load and taste. J Clin Periodontol 2004;31:506-10.

29. Pratibha PK, Bhat KM, Bhat GS. Oral malodor: A review of the literature. J Dent Hyg 2006;80:8.

30. Gondhalekar R, Richard KM, Jayachandra MG, Aslam S, Reddy VN Barabde AS. Effect of tongue cleaning methods and oral mutans streptococci level. J Contemp Dent Pract 2013;14:119-22.

31. Casemiro LA, Martins CH, de Carvalho TC, Panzeri H, Lavrador MA Pires-de-Souza Fde C. Effectiveness of a new toothbrush design versus a conventional tongue scraper in improving breath odor and reducing tongue microbiota. J Appl Oral Sci 2008;16:271-4.

32. Almas K, Al-Sanawi E, Al-Shahrani B. The effect of tongue scraper on mutans streptococci and lactobacilli in patients with caries and periodontal disease. Odontostomatol Trop 2005;28:5-10.

33. Bordas A, McNab R, Staples AM, Bowman J, Kanapka J, Bosma MP. Impact of different tongue cleaning methods on the bacterial load of the tongue dorsum. Arch Oral Biol 2008;53 Suppl 1:S13-8.

34. Gulati MS, Gupta L. Clinical evaluation of supplementing tongue brushing to most advocated regime of tooth brushing. J Indian Soc Pedod Prev Dent 1998;16:12-6. 
Manju, et al.: Comparative evaluation of adjunctive oral hygiene measures

35. Winnier JJ, Rupesh S, Nayak UA, Reddy V, Prasad Rao A. The comparative evaluation of the effects of tongue cleaning on existing plaque levels in children. Int J Clin Pediatr Dent 2013;6:188-92.

36. De Boever EH, Loesche WJ. Assessing the contribution of anaerobic microflora of the tongue to oral malodor. J Am Dent Assoc 1995;126:1384-93.

37. Rupesh S, Winnier JJ, Nayak UA, Rao AP, Reddy NV. Comparative evaluation of the effects of an alum-containing mouthrinse and a saturated saline rinse on the salivary levels of Streptococcus mutans. J Indian Soc Pedod Prev Dent 2010;28:138-44.

\begin{tabular}{|l|l|}
\hline \multicolumn{2}{|c|}{ Access this article online } \\
\hline Quick Response Code: \\
\hline
\end{tabular}

